University of Nebraska - Lincoln

DigitalCommons@University of Nebraska - Lincoln

Publications, Agencies and Staff of the U.S.

Department of Commerce

U.S. Department of Commerce

2010

Eco-evolutionary dynamics: fluctuations in population growth rate reduce effective population size in chinook salmon

Robin Waples

NOAA, robin.waples@noaa.gov

David Jensen

Northwest Fisheries Science Center

Michelle McClure

Northwest Fisheries Science Center

Follow this and additional works at: https://digitalcommons.unl.edu/usdeptcommercepub

Waples, Robin; Jensen, David; and McClure, Michelle, "Eco-evolutionary dynamics: fluctuations in population growth rate reduce effective population size in chinook salmon" (2010). Publications, Agencies and Staff of the U.S. Department of Commerce. 450.

https://digitalcommons.unl.edu/usdeptcommercepub/450

This Article is brought to you for free and open access by the U.S. Department of Commerce at DigitalCommons@University of Nebraska - Lincoln. It has been accepted for inclusion in Publications, Agencies and Staff of the U.S. Department of Commerce by an authorized administrator of DigitalCommons@University of Nebraska - Lincoln. 


\title{
Eco-evolutionary dynamics: fluctuations in population growth rate reduce effective population size in chinook salmon
}

\author{
Robin S. Waples, ${ }^{1}$ David W. Jensen, ${ }^{2}$ and Michelle McClure \\ National Marine Fisheries Service, Northwest Fisheries Science Center, Seattle, Washington 98112 USA
}

\begin{abstract}
We empirically assess the relationship between population growth rate $(\lambda$, a parameter central to ecology) and effective population size ( $N_{\mathrm{e}}$, a key parameter in evolutionary biology). Recent theoretical and numerical studies indicate that in semelparous species with variable age at maturity (such as Pacific salmon, many monocarpic plants, and various other species), differences in mean reproductive success among individuals reproducing in different years leads to variation in $\lambda$, and this in turn can reduce $N_{\mathrm{e}}$. However, this phenomenon has received little empirical evaluation. We examined time series of abundance data for 56 populations of chinook salmon (Onchorhynchus tshawytscha) from the northwestern United States and compared $N_{\mathrm{e}}$ (calculated from demographic data) with the total number of spawners each generation $\left(N_{\mathrm{T}}\right)$. Important results include: (1) The mean multigenerational ratio $\tilde{N}_{\mathrm{e}} / \tilde{N}_{\mathrm{T}}$ was 0.64 (median $=0.67$ ), indicating that annual variation in $\lambda$ reduces effective population size in chinook salmon by an average of $\sim 35 \%$. These reductions are independent of, and in addition to, factors that reduce $N_{\mathrm{e}}$ within individual cohorts (uneven sex ratio and greater-than-random variance in reproductive success). (2) The coefficient of variation of $\lambda$ was the most important factor associated with reductions in $N_{\mathrm{e}}$, explaining up to two-thirds of the variance in $\tilde{N}_{\mathrm{e}} / \tilde{N}_{\mathrm{T}}$. (3) Within individual generations, $N_{\mathrm{e}}$ was lower when there was a negative correlation between annual $N_{i}$ and $\lambda$, i.e., when relatively few breeders produced relatively high numbers of offspring. Our results thus highlight an important and little-studied eco-evolutionary trade-off: density-dependent compensation has generally favorable ecological consequences (promoting stability and long-term viability) but incurs an evolutionary cost (reducing $N_{\mathrm{e}}$ because a few individuals make a disproportionate genetic contribution). (4) For chinook salmon, $\hat{N}_{\mathrm{eH}}$ (an estimator based on the harmonic mean number of breeders per year) is generally a good proxy for true $N_{\mathrm{e}}$ and requires much less data to calculate.
\end{abstract}

Key words: age-structured species; chinook salmon; eco-evolutionary trade-offs; ideal population; northwestern United States; Onchorhynchus tshawytscha; recruits per spawner; reproductive success; semelparous.

\section{INTRODUCTION}

Population growth rate $(\lambda)$ is one of the most fundamental parameters in ecology. A population's growth rate can be used to define its ecological niche (Hooper et al. 2008), test life history theory (Seamans and Gutierrez 2007), study dynamics of infectious disease (Bacaer and Ouifki 2007), examine spatial patterns of autocorrelation (Jones et al. 2007), or evaluate biological consequences of climate change (Hone and Clutton-Brock 2007), to name just a few applications. In addition, the mean and variance of $\lambda$ are essential in assessing population viability (Beissinger and $\mathrm{McCul}-$ lough 2002, Boyce et al. 2006) and evaluating effects of conservation measures for species at risk (Wisdom et al. 2000, Van der Voort and McGraw 2006).

Manuscript received 6 March 2009; revised 10 June 2009; accepted 15 June 2009. Corresponding Editor: M. FestaBianchet.

${ }^{1}$ E-mail: robin.waples@noaa.gov

2 Present address: 710 West 27 th Avenue, Eugene, Oregon 97405 USA.
In evolutionary biology, effective population size $\left(N_{\mathrm{e}}\right)$ plays a similarly central role. Effective population size, rather than census size $(N)$, determines rates of random genetic drift, allele frequency change, loss of genetic variability, and increase in inbreeding (Kimura 1983). Effective size also determines the relative importance of natural selection and migration, which have predictable effects in large populations but can be overwhelmed by drift when $N_{\mathrm{e}}$ is small (Felsenstein 1976). Considerable interest has focused on the ratio of effective : census size $\left(N_{\mathrm{e}} / N\right)$, which can vary substantially among species (Frankham 1995) and might be very small in some (Hedrick 2005). Understanding and estimating $N_{\mathrm{e}}$ is particularly important in conservation of small populations, for which random processes can be a potent evolutionary force (Allendorf and Luikart 2007).

In this paper, we consider the relationship between these two key parameters, one ecological, the other evolutionary. Recent theoretical and numerical studies (Nunney 2002, Waples 2002, 2006, Vitalis et al. 2004) have evaluated $N_{\mathrm{e}}$ in species that are semelparous but have variable age at maturity, life history traits that 
characterize Pacific salmon (Onchorhynchus spp.). Variable age at maturity is also found in many monocarpic plants, such as desert annuals (Venable 2007), Agave spp. (Nobel 1992), and many bamboos (Kitamura and Kawahara 2009). Many invertebrate species with diapausing eggs, such as Daphnia spp. (Caceres and Tessier 2004) and copepods (Hairston and Munns 1984), also have variation in time of maturity in spite of reproducing during only one season. Here, we use empirical data for over 50 populations of chinook salmon (O.tshawytscha) to evaluate the influence of variation in population growth rate and other demographic parameters on effective population size.

Evolutionary biologists use hypothetical "ideal" populations to make the concept of effective size operational. An ideal population has discrete generations, constant size, equal sex ratio, and binomial variation among individuals in reproductive success; if these conditions are met, $N_{\mathrm{e}}=N$. However, few if any natural populations completely satisfy these conditions, with the general result that $N_{\mathrm{e}} / N<1$. Within a particular generation, greater-than-random variance in reproductive success is the primary factor that reduces $N_{\mathrm{e}}$ compared to $N$ (Frankham 1995). Semelparous, age-structured species also depart from the ideal model because individuals within a generation do not mate at random; instead, they mate only with others that mature in the same year, and the resulting progeny represent the lifetime reproductive success of those parents. Because $N$ varies over time in all natural populations, mean reproductive success of individuals in different years will also vary, as will $\lambda$. This means that, within any given generation, different groups of individuals will have different mean reproductive output, a fact that increases variance in reproductive success (among all the individuals within a generation) and reduces $N_{\mathrm{e}}$ (Waples 2002, 2006). Notably, this will be true even if the individuals that breed each year are "ideal" in all other respects.

Previous studies (Nunney 2002, Waples 2002, 2006) evaluated how various demographic parameters (age structure, generation length, variance in $N$ and $\lambda$, method of population regulation) affect $N_{\mathrm{e}}$ and $N_{\mathrm{e}} / N$. In this paper, we ask the following questions based on empirical data for chinook salmon: (1) What is the magnitude of reduction in $N_{\mathrm{e}}$ and $N_{\mathrm{e}} / N$ per generation associated with variation in population growth rate, and does this differ among life history types and geographic areas? (2) What demographic or life history characteristics are most important in determining the $N_{\mathrm{e}} / N$ ratio? (3) How well does a simple method that uses a time series of abundance data perform in estimating true effective size in these populations?

\section{Methods Selection of populations}

We examined abundance data for 79 populations of chinook salmon from Washington, Oregon, Idaho, and California, USA, and 56 of these met our selection criteria (Table 1, Fig. 1): at least 10 years of continuous data, including yearly estimates of numbers of spawners $\left(N_{i}\right)$ and naturally produced recruits $\left(R_{i}\right.$, adult spawners in subsequent years produced by the spawners in year $i$ ). Data series ranged in length from 10 to 42 years and included populations at both high and low abundance. The populations can be grouped into two hierarchical levels. First, populations spawning in high-elevation tributaries of the Interior Columbia River basin are from a genetic lineage that is well isolated from other chinook salmon (Waples et al. 2004; Fig. 2). These upper-tributary populations are commonly said to have a "stream-type" life history because as juveniles they spend an entire winter in fresh water before migrating to sea as yearling smolts, and as adults they begin their spawning migration in spring or summer and mature in fresh water (Healey 1991). In contrast, most "oceantype" populations (in the Columbia River, in Puget Sound, and in coastal streams) are dominated by subyearling smolts, mature at sea, and spawn shortly after returning to fresh water. Second, within each life history type, the populations are drawn from multiple evolutionarily significant units (ESUs). Salmon ESUs are defined based on differences in ecological, life history, and genetic characteristics and are intended to identify groups of populations that are largely following independent evolutionary trajectories (Waples 1991). Therefore, we expected that biological and/or ecological differences associated with life history types and ESUs might differentially influence effective population size.

We examined associations between estimates of effective size and several demographic characteristics that previous work suggests might affect $N_{\mathrm{e}}$. Mean $N_{i}$ varied by more than two orders of magnitude among populations, from 115 (Big Creek) to over 40000 (Hanford Reach) (Table 1). The coefficient of variation of population size was high $\left[\mathrm{CV}\left(N_{i}\right)>0.5\right]$ in most populations. The number of years of data differed significantly between the two life history types, with means of $n=18.8$ years in ocean-type populations and 34.7 years in stream-type populations. However, as discussed below (Results: Factors associated ... and Factors affecting ... ) we found no evidence that results were sensitive to data series length. Mean age at spawning (which provides an estimate of generation length, $g$ ) was 3.5-4.5 yr in most ocean-type populations and between 4 and $5 \mathrm{yr}$ in all stream-type populations (Table 1). It is likely that actual generation length was slightly higher because older individuals tend to produce more offspring (Healey and Heard 1984). We calculated an evenness age index for each population as $I$ $=1-\Sigma A_{x}^{2}$, where $A_{x}$ is the fraction maturing at each age $\left(\Sigma A_{x}=1\right)$. When all adults reproduce at a single age, $I$ is 0 and takes a maximum of $1-1 / a$ when $A_{x}$ is equal over each of $a$ age classes. Values for most populations fell within a rather narrow range $(I=0.5-0.65$; Table 1$)$.

The annual measure of population growth rate, $\lambda_{i}=$ $R_{i} / N_{i}$, is lognormally distributed in salmon (Peterman $1981)$, so we used the geometric mean $\left[\operatorname{GM}\left(\lambda_{i}\right)\right]$ as an 
TABLE 1. Summary information for populations of chinook salmon (Onchorhynchus tshawytscha) considered in this paper, by ocean-type and stream-type life history.

\begin{tabular}{|c|c|c|c|c|c|c|c|c|c|c|c|c|c|c|}
\hline \multirow[b]{2}{*}{ Population by ESU } & \multicolumn{3}{|c|}{ Years } & \multicolumn{2}{|c|}{$\begin{array}{c}\text { Annual } \\
\text { number of } \\
\text { spawners, } N_{i} \\
\end{array}$} & \multicolumn{3}{|c|}{$\begin{array}{c}\text { Recruits } \\
\text { per spawner, } \\
\lambda\end{array}$} & \multicolumn{4}{|c|}{ Age at maturity, $A_{i}$} & \multirow[b]{2}{*}{$\begin{array}{c}g \\
(\mathrm{yr})\end{array}$} & \multirow{2}{*}{$\begin{array}{c}\text { Even- } \\
\text { ness } \\
\text { age } \\
\text { index, } \\
I\end{array}$} \\
\hline & $n$ & First & Last & Mean & $\mathrm{CV}$ & Mean & GM & $\mathrm{CV}$ & 2 & 3 & 4 & $\geq 5$ & & \\
\hline \multicolumn{15}{|l|}{ Ocean type } \\
\hline \multicolumn{15}{|l|}{ Puget Sound } \\
\hline Bridal Veil & 16 & 1979 & 1994 & 566 & 0.32 & 1.10 & 0.98 & 0.48 & 0.01 & 0.01 & 0.56 & 0.29 & 3.75 & 0.61 \\
\hline Cedar River & 31 & 1964 & 1994 & 817 & 0.52 & 1.12 & 0.94 & 0.68 & 0.01 & 0.26 & 0.69 & 0.04 & 3.75 & 0.46 \\
\hline Duwamish/Green Rivers & 27 & 1968 & 1994 & 5281 & 0.53 & 1.36 & 1.07 & 0.71 & 0.03 & 0.18 & 0.72 & 0.07 & 3.84 & 0.44 \\
\hline Elwha River & 18 & 1976 & 1993 & 2068 & 0.75 & 1.65 & 1.17 & 0.98 & 0.01 & 0.13 & 0.57 & 0.3 & 4.17 & 0.58 \\
\hline Lower Sauk River & 21 & 1974 & 1994 & 1016 & 0.62 & 1.21 & 0.88 & 0.77 & 0.00 & 0.10 & 0.67 & 0.23 & 4.13 & 0.49 \\
\hline Lower Skagit River & 21 & 1974 & 1994 & 2710 & 0.48 & 0.92 & 0.84 & 0.43 & 0.03 & 0.23 & 0.53 & 0.2 & 3.91 & 0.62 \\
\hline North Fork Nooksack River & 11 & 1984 & 1994 & 232 & 0.75 & 3.19 & 1.68 & 1.13 & 0.00 & 0.05 & 0.90 & 0.05 & 4.00 & 0.19 \\
\hline South Fork Nooksack River & 11 & 1984 & 1994 & 300 & 0.55 & 0.98 & 0.90 & 0.40 & 0.01 & 0.10 & 0.60 & 0.29 & 4.17 & 0.54 \\
\hline Skokomish River & 27 & 1968 & 1994 & 1387 & 0.59 & 1.82 & 1.00 & 1.71 & 0.14 & 0.69 & 0.15 & 0.02 & 3.05 & 0.48 \\
\hline Snohomish River, fall & 12 & 1983 & 1994 & 1770 & 0.35 & 1.11 & 1.01 & 0.45 & 0.00 & 0.05 & 0.48 & 0.48 & 4.43 & 0.54 \\
\hline Snohomish River, summer & 15 & 1979 & 1993 & 952 & 0.55 & 1.12 & 0.97 & 0.52 & 0.00 & 0.20 & 0.55 & 0.24 & 4.04 & 0.60 \\
\hline Stillaguamish Riv & 10 & 1985 & 1994 & 140 & 0.35 & 1.42 & 1.28 & 0.45 & 0.11 & 0.35 & 0.50 & 0.04 & 3.47 & 0.61 \\
\hline Stillaguamish Rive & 21 & 1974 & 1994 & 812 & 0.45 & 1.17 & 1.00 & 0.58 & 0.05 & 0.29 & 0.51 & 0.15 & 3.76 & 0.63 \\
\hline Suiattle River & 27 & 1967 & 1993 & 642 & 0.56 & 1.05 & 0.87 & 0.55 & 0.01 & 0.07 & 0.46 & 0.45 & 4.37 & 0.58 \\
\hline Cascade River & 10 & 1984 & 1993 & 188 & 0.46 & 1.41 & 1.25 & 0.49 & 0.03 & 0.13 & 0.66 & 0.19 & 4.01 & 0.51 \\
\hline Upper Sauk River & 28 & 1967 & 1994 & 562 & 0.69 & 1.53 & 1.05 & 0.94 & 0.03 & 0.14 & 0.24 & 0.59 & 4.38 & 0.58 \\
\hline Upper $S$ & 21 & 1974 & 1994 & 7513 & 0.40 & 1.15 & 1.04 & 0.50 & 0.01 & 0.17 & 0.56 & 0.26 & 4.07 & 0.59 \\
\hline Wallace River & 15 & 1979 & 1993 & 901 & 0.76 & 1.48 & 0.84 & 1.47 & 0.00 & 0.19 & 0.51 & 0.29 & 4.11 & 0.62 \\
\hline \multicolumn{15}{|l|}{ Lower Columbia } \\
\hline Big White Salmon & 18 & 1978 & 1995 & 523 & 0.96 & 1.01 & 0.69 & 0.87 & 0.05 & 0.41 & 0.47 & 0.06 & .54 & 0.60 \\
\hline $\mathrm{Co}$ & 18 & 1978 & 1995 & 299 & 1.06 & 2.82 & 1.85 & 0.86 & 0.03 & 0.19 & 0.55 & 0.23 & 96 & 0.61 \\
\hline Cowlitz River & 17 & 1978 & 1994 & 2898 & 0.66 & 0.34 & 0.24 & 0.84 & 0.33 & 0.18 & 0.26 & 0.24 & 3.40 & 0.74 \\
\hline East Fork, Lewis River Tules & 16 & 1980 & 1995 & 337 & 0.42 & 1.09 & 0.85 & 0.72 & 0.03 & 0.21 & 0.55 & 0.21 & 3.93 & 0.61 \\
\hline Elochoman River & 18 & 1978 & 1995 & 679 & 1.03 & 1.05 & 0.50 & 1.13 & 0.14 & 0.47 & 0.35 & 0.04 & 3.29 & 0.64 \\
\hline Grays & 18 & 1978 & 1995 & 644 & 1.03 & 1.56 & 0.58 & 1.52 & 0.05 & 0.27 & 0.57 & 0.12 & 3.75 & 0.59 \\
\hline Kalc & 18 & 1978 & 1995 & 5631 & 1.15 & .16 & 0.61 & 1.40 & 0.02 & 0.34 & 0.40 & 0.24 & 3.86 & 0.67 \\
\hline Lewis River Bright & 18 & 1978 & 1995 & 12626 & 0.40 & 1.02 & 0.78 & 0.63 & 0.08 & 0.13 & 0.38 & 0.4 & 4.11 & 0.67 \\
\hline Mill Creek & 16 & 1980 & 1995 & 2094 & 0.75 & 0.90 & 0.50 & 1.22 & 0.08 & 0.40 & 0.43 & 0.09 & 3.54 & 0.64 \\
\hline $\mathrm{S}$ & 13 & 1984 & 1996 & 1052 & 0.57 & 1.24 & 0.96 & 0.76 & 0.07 & & 0.62 & 0.09 & 3.73 & 0.56 \\
\hline $\mathrm{W}$ & 18 & 1978 & 1995 & 2597 & 0.46 & 0.69 & 0.47 & 0.88 & 0.10 & 0.25 & 0.55 & 0.1 & 3.66 & 0.61 \\
\hline Wind River & 15 & 1978 & 1992 & 462 & 0.99 & 1.15 & 0.45 & 1.62 & 0.03 & 0.47 & 0.46 & 0.04 & 3.51 & 0.57 \\
\hline Interior C & & & & & & & & & & & & & & \\
\hline & 3 & 1964 & 1991 & 40171 & 0.63 & 2 & 0.92 & 0.78 & 0.32 & 0.19 & 0.34 & 0.16 & 3.34 & 0.73 \\
\hline Snake River & 28 & 1964 & 1991 & 4129 & 1.22 & 0.88 & 0.77 & 0.52 & 0.35 & 0.34 & 0.26 & 0.05 & 3.01 & 0.69 \\
\hline Southern Oregc & & & & & & & & & & & & & & \\
\hline Rogue River & 18 & 1977 & 1994 & 8868 & 1.03 & 2.16 & 0.83 & 1.62 & 0.11 & 0.25 & 0.51 & 0.13 & 3.67 & 0.65 \\
\hline Ocean-type means & 19 & & & 3359 & 0.67 & 1.34 & 0.91 & 0.88 & 0.07 & 0.23 & 0.50 & 0.20 & 3.81 & 0.58 \\
\hline tream & & & & & & & & & & & & & & \\
\hline Snake River, spring/ & & & & & & & & & & & & & & \\
\hline Bear Valley Creek & 36 & 1962 & 1997 & 668 & 0.96 & 1.38 & 0.77 & 1.20 & 0.00 & 0.02 & 0.40 & 0.58 & 4.56 & 0.51 \\
\hline Big Cre & 35 & 1962 & 1996 & 115 & 0.91 & 1.98 & 0.79 & 1.94 & 0.00 & 0.06 & 0.40 & 0.54 & 4.49 & 0.54 \\
\hline Creek & 40 & 1958 & 1997 & 508 & 0.92 & 1.11 & 0.58 & 0.99 & 0.00 & 0.09 & 0.64 & 0.27 & 4.19 & 0.51 \\
\hline Imnaha River & 42 & 1955 & 1996 & 963 & 0.80 & 0.83 & 0.60 & 0.80 & 0.00 & 0.04 & 0.47 & 0.49 & 4.45 & 0.55 \\
\hline Johnson Creek & 35 & 1962 & 1996 & 288 & 0.79 & 0.97 & 0.74 & 0.75 & 0.00 & 0.07 & 0.53 & 0.39 & 4.32 & 0.56 \\
\hline Lemhi River & 35 & 1962 & 1996 & 602 & 1.04 & 1.41 & 0.75 & 1.55 & 0.00 & 0.01 & 0.49 & 0.5 & 4.49 & 0.51 \\
\hline Lookingglass & 40 & 1955 & 1994 & 418 & 1.24 & 0.85 & 0.52 & 0.89 & 0.00 & 0.13 & 0.64 & 0.22 & 4.08 & 0.52 \\
\hline River & 42 & 1955 & 1996 & 263 & 0.71 & 1.21 & 0.70 & 1.27 & 0.00 & 0.06 & 0.58 & 0.36 & 4.30 & 0.53 \\
\hline Marsh Creek & 36 & 1962 & 1997 & 374 & 0.93 & 1.35 & 0.66 & 1.52 & 0.00 & 0.04 & 0.37 & 0.59 & 4.56 & 0.52 \\
\hline Minam River & 38 & 1959 & 1996 & 289 & 0.73 & 1.26 & 0.71 & 1.14 & 0.00 & 0.07 & 0.67 & 0.26 & 4.19 & 0.48 \\
\hline Poverty Flat & 35 & 1962 & 1996 & 697 & 0.91 & 0.92 & 0.71 & 0.75 & 0.00 & 0.10 & 0.53 & 0.37 & 4.27 & 0.58 \\
\hline Secesh River & 35 & 1962 & 1996 & 247 & 0.60 & 1.13 & 0.85 & 0.77 & 0.00 & 0.08 & 0.55 & 0.36 & 4.28 & 0.56 \\
\hline Sulphur Creek & 22 & 1962 & 1983 & 358 & 0.85 & 2.38 & 0.83 & 1.43 & 0.00 & 0.04 & 0.38 & 0.58 & 4.55 & 0.53 \\
\hline Upper Grande Ronde River & 40 & 1959 & 1998 & 373 & 0.85 & 0.99 & 0.55 & 1.11 & 0.00 & 0.08 & 0.64 & 0.28 & 4.20 & 0.51 \\
\hline Valley Creek & 32 & 1962 & 1993 & 178 & 1.08 & 2.31 & 0.68 & 2.22 & 0.00 & 0.07 & 0.35 & 0.58 & 4.51 & 0.53 \\
\hline Wenaha River & 31 & 1966 & 1996 & 662 & 1.08 & 0.67 & 0.48 & 0.78 & 0.00 & 0.05 & 0.64 & 0.3 & 4.25 & 0.49 \\
\hline Mid-Columbia & & & & & & & & & & & & & & \\
\hline Middle Fork, Joh & 32 & 1965 & 1996 & 394 & 0.68 & 1.87 & 1.19 & 1.31 & 0.00 & 0.03 & 0.85 & 0.12 & 4.09 & 0.26 \\
\hline North Fork, John Day River & 33 & 1964 & 1996 & 1611 & 0.44 & 1.16 & 0.92 & 0.80 & 0.00 & 0.03 & 0.80 & 0.17 & 4.14 & 0.33 \\
\hline Upper John Day River & 33 & 1964 & 1996 & 318 & 0.59 & 1.41 & 1.09 & 0.88 & 0.00 & 0.05 & 0.88 & 0.07 & 4.03 & 0.22 \\
\hline Warm Springs River & 21 & 1974 & 1994 & 788 & 0.60 & 1.09 & 0.75 & 0.83 & 0.00 & 0.05 & 0.77 & 0.18 & 4.13 & 0.37 \\
\hline
\end{tabular}


TABLE 1. Continued.

\begin{tabular}{|c|c|c|c|c|c|c|c|c|c|c|c|c|c|c|}
\hline \multirow[b]{2}{*}{ Population by ESU } & \multicolumn{3}{|c|}{ Years } & \multicolumn{2}{|c|}{$\begin{array}{c}\text { Annual } \\
\text { number of } \\
\text { spawners, } N_{i}\end{array}$} & \multicolumn{3}{|c|}{$\begin{array}{c}\text { Recruits } \\
\text { per spawner, } \\
\lambda\end{array}$} & \multicolumn{4}{|c|}{ Age at maturity, $A_{i}$} & \multirow[b]{2}{*}{$\begin{array}{l}g \\
(\mathrm{yr})\end{array}$} & \multirow{2}{*}{$\begin{array}{c}\text { Even- } \\
\text { ness } \\
\text { age } \\
\text { index, } \\
I\end{array}$} \\
\hline & $n$ & First & $\overline{\text { Last }}$ & Mean & $\mathrm{CV}$ & Mean & GM & $\overline{C V}$ & 2 & 3 & 4 & $\geq 5$ & & \\
\hline \multicolumn{15}{|l|}{ Upper Columbia } \\
\hline Entiat River & 37 & 1960 & 1996 & 371 & 0.74 & 1.11 & 0.80 & 0.83 & 0.00 & 0.08 & 0.61 & 0.32 & 4.24 & 0.53 \\
\hline Methow River & 31 & 1960 & 1990 & 1673 & 0.62 & 1.08 & 0.81 & 0.75 & 0.00 & 0.10 & 0.54 & 0.36 & 4.26 & 0.57 \\
\hline Wenatchee River & 37 & 1960 & 1996 & 2445 & 0.62 & 1.16 & 0.76 & 0.94 & 0.00 & 0.07 & 0.50 & 0.43 & 4.36 & 0.56 \\
\hline Stream-type means & 35 & & & 635 & 0.81 & 1.29 & 0.75 & 1.11 & 0.00 & 0.06 & 0.58 & 0.36 & 4.30 & 0.49 \\
\hline
\end{tabular}

Notes: We examined abundance data for 79 populations of chinook salmon from Washington, Oregon, Idaho, and California, USA, and 56 of these met our selection criteria. The evenness age index, $I$, was calculated as $I=1-\Sigma A_{x}^{2}$, where $A_{x}$ is the fraction maturing at each age. Abbreviations are: CV, coefficient of variation; GM, geometric mean; g, generation length; ESU, evolutionarily significant unit.

$\dagger$ This group includes two closely related ESUs, each represented here by a single population.

indication of population trend. The geometric mean was close to 1 in Puget Sound (mean = 1.04) but was substantially lower in the Lower Columbia River (mean $=0.72 ; 95 \%$ distribution-free $\mathrm{CI}=0.50-0.85)$ and Snake River spring/summer $(0.68 ; \mathrm{CI}=0.60-0.77)$ ESUs. The coefficient of variation of population size, $\operatorname{CV}\left(\lambda_{i}\right)$, was generally high $(>0.5)$, particularly so in many Columbia River populations. That is, although some populations had stable trends, many others were declining over the study period, and most had a high interannual variance in productivity.

\section{Run reconstructions}

Data for populations within the Puget Sound, Lower Columbia, Upper Columbia, and Snake Rivers spring/ summer and fall ESUs were compiled for a review of populations listed as threatened or endangered "species" under the U.S. Endangered Species Act (Good et al. 2005). Other sources were: Interior Columbia oceantype (Peters et al. 1999), Mid-Columbia (Beamesderfer et al. 1998, as updated by Oregon Department of Fish and Wildlife staff; E. Tinus, personal communication),

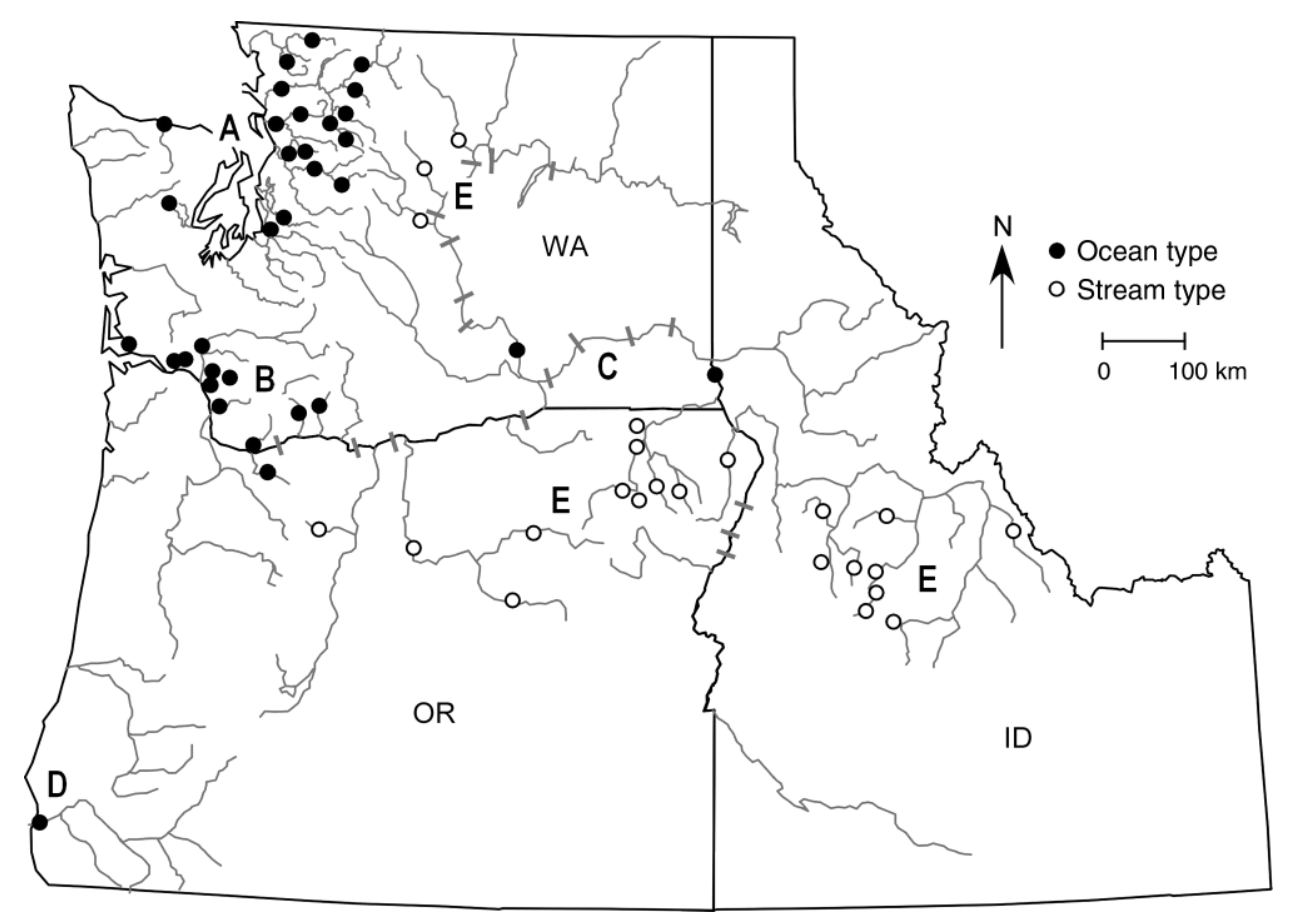

FIG. 1. Map of the northwestern United States showing locations of 56 populations of chinook salmon (Onchorhynchus tshawytscha) considered in the analyses. Stream type and ocean type are two major life history variants described in the paper. Letters indicate geographic regions and run timing: A, Puget Sound; B, Lower Columbia; C, Interior Columbia, fall-run; D, Rogue River; E, Interior Columbia, spring/summer-run. State abbreviations are: WA, Washington; OR, Oregon; ID, Idaho. 


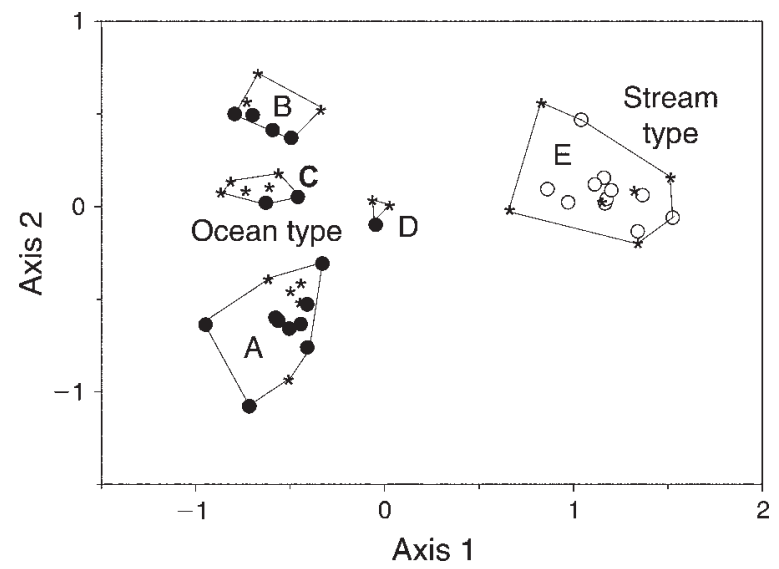

FIG. 2. Multidimensional scaling plot of pairwise genetic distances (chord distance; Cavalli-Sforza and Edwards 1967) among samples from 48 chinook salmon populations from several geographic regions. Solid circles, ocean-type populations included in this study; open circles, stream-type populations included in this study; stars, populations from nearby areas with genetic data considered by Waples et al. (2004). Geographic/run timing designations $(\mathrm{A}-\mathrm{E})$ are as illustrated in Fig. 1.

and Rogue River (Whisler and Jacobs 2001). Yearly estimates of $N_{i}$ were derived from surveys of redds (salmon nests) or counts of fish passing weirs or dams, expanded to population scale using estimates of available spawning habitat, pre-spawning mortality, and other factors (such as harvest) as appropriate. The description of expansion methods in Beamesderfer et al. (1998) is typical for other ESUs as well.

Yearly estimates of spawner ages were available for many populations, but in Puget Sound (and for earlier years in other data series) mean age structure was used. Age was generally determined from scales, occasionally from length. For each population, we obtained a vector of adult recruits $\left(R_{i}\right)$ as follows. Spawners in each year were partitioned into cohorts based on $A_{x}$ values and assigned backwards to the parental brood year. For example, in year $i$, three-year-old spawners would be assigned as recruits to year $i-3$, four-year-old spawners to year $i-4$, and five-year-old spawners to year $i-5$. The time series of recruits was necessarily one generation shorter than that for spawners. Some populations were influenced by naturally spawning hatchery fish. Because all natural spawners can contribute genes to subsequent generations, we included naturally spawning hatchery fish in the $N_{i}$, but recruits included only fish whose parents spawned in the wild.

We have not attempted a formal assessment of effects of uncertainty in estimating key demographic parameters $\left(N_{i}, R_{i}\right)$ because published quantitative estimates of measurement error are not available; however, recent work suggests that the high variability in abundance seen among years for chinook salmon is not driven by measurement error (Paulsen et al. 2007). Instead, we attempted to restrict analyses to data sets for which sampling methods were consistent across years and comparable across populations. We believe that most measurement errors contributed random noise and perhaps have helped obscure some underlying patterns, but have not produced spurious results. We note, however, one potential source of bias that arises from random ageing errors: this will tend to overestimate the number of recruits (and hence $\lambda_{i}$ ) for years with low $N_{i}$. This occurs because such years generally produce relatively few recruits, and only a few of these are incorrectly assigned (by chance) to the wrong parental year. Adjacent years with higher $N_{i}$ will, on average, produce more recruits and hence more chances for a recruit to be incorrectly assigned to the year with low $N_{i}$. A similar bias can result from using a long-term average age structure (rather than data for each brood year) to assign recruits to parental year (Zabel and Levin 2002). Therefore, we expect there might be a general tendency to overestimate $\lambda_{i}$ in years with low $N_{i}$, which could downwardly bias $\tilde{N}_{\mathrm{e}} / \tilde{N}_{\mathrm{T}}$. In the future, it will be important to try to quantify the magnitude of this potential effect in empirical data sets for which measurement error can be assessed.

\section{Effective population size}

We are concerned primarily with three quantities related to population size: $N_{\mathrm{T}}$, total census size for a generation; $N_{\mathrm{e}}$, true effective population size for a generation, and $\hat{N}_{\mathrm{eH}}$, an estimate of $N_{\mathrm{e}}$ obtained by the harmonic mean method. The total census size is simply the total number of spawners in the generation, $\Sigma N_{i}$. It is also the product of the generation length $\left(g=\Sigma x A_{x}\right)$ and the mean $N_{i}$ within a generation:

$$
N_{\mathrm{T}}=g \bar{N}_{i}=g \frac{\sum_{i=1}^{g} N_{i}}{g}
$$

which shows that $N_{\mathrm{T}}$ is the same quantity obtained using the arithmetic mean method proposed by Nunney (2002).

To calculate $N_{\mathrm{e}}$, we used the method described by (Waples 2002, 2006), which accounts for variations in productivity across years within a generation:

$$
N_{\mathrm{e}}=\frac{1}{\sum_{i=1}^{g} \frac{\left(R_{i} / R_{\mathrm{T}}\right)^{2}}{N_{i}}}
$$

where $R_{\mathrm{T}}$ is the total number of recruits produced by all spawners within the generation. This method accurately tracked the accumulation of inbreeding in modeled populations under a variety of scenarios (Waples 2006), so there is a sound basis for considering the quantity shown in Eq. 2 to be the true effective size.

As Eq. 2 requires detailed demographic information, we evaluated an estimator that is less data intensive. The harmonic mean method requires only a time series of $N_{i}$ values: 


$$
\hat{N}_{\mathrm{eH}}=g \tilde{N}_{i}=\frac{g^{2}}{\sum_{i=1}^{g} \frac{1}{N_{i}}}
$$

where $\tilde{N}_{i}$ is the harmonic mean of the $N_{i}$. Because $\hat{N}_{\mathrm{eH}}$ weights years of low abundance more heavily, it will always be less than $N_{\mathrm{T}}$ if population size varies.

As generation length for most populations was four to five years, annual $N_{i}$ and $R_{i}$ values were grouped into fiveyear generations, with the last generation ending with the most recent year of data. Within each generation, we calculated the quantities in Eqs. 1-3, using (separately) all five years and only the first four, and we also computed the ratios $N_{\mathrm{e}} / N_{\mathrm{T}}$ and $N_{\mathrm{e}} / \hat{N}_{\mathrm{eH}}$ separately for the four- and five-year time series. A few populations had one year with estimated $N_{i}=0$; we dropped these years from the analysis and used the remaining three or four years of data for that generation. Across multiple generations, rates of evolutionary processes scale with the harmonic mean of single-generation $N_{\mathrm{e}}$ values (Wright 1938). Therefore, multigenerational values $\left(\tilde{N}_{\mathrm{T}}, \tilde{N}_{\mathrm{e}}, \tilde{N}_{\mathrm{eH}}\right)$ were calculated as the harmonic means of the single-generation values, and multigenerational ratios for each population were calculated as $\tilde{N}_{\mathrm{e}} / \tilde{N}_{\mathrm{T}}$ and $\tilde{N}_{\mathrm{e}} / \tilde{N}_{\mathrm{eH}}$ (see Kalinowski and Waples [2002] for discussion of multigenerational $N_{\mathrm{e}} / N$ ratios). Note that, for simplicity, we drop the "^" from $\hat{N}_{\mathrm{eH}}$ for multigenerational values. The $N_{\mathrm{e}} / N_{\mathrm{T}}$ values for four- and five-year generations were tightly correlated (all $r \geq 0.90$ across all populations; $P<$ 0.001 ), and a similar result was found for $N_{\mathrm{e}} / \hat{N}_{\mathrm{eH}}$. Furthermore, Mann-Whitney tests found no evidence that either $N_{\mathrm{e}} / N_{\mathrm{T}}$ or $N_{\mathrm{e}} / N_{\mathrm{eH}}$ calculated from four-year and five-year generation length differed $(U=1382, Z$ [approximate] $=1.0795, P=0.28$ for both). Therefore, for each population we calculated combined $\tilde{N}_{\mathrm{e}} / \tilde{N}_{\mathrm{T}}$ and $\tilde{N}_{\mathrm{e}} / \tilde{N}_{\mathrm{eH}}$ as the geometric mean of the four- and five-year multigenerational ratios.

Across all 56 populations, the distribution of $\tilde{N}_{\mathrm{e}} / \tilde{N}_{\mathrm{T}}$ was slightly skewed left (mean $=0.64$, median $=0.67$; Kolmogorov-Smirnov test, $P<0.019$ ), so the median and distribution-free confidence intervals (after Hahn and Meeker 1991) were used to describe central tendency. However, within the two major life history types, and for each of the three ESUs with enough populations for meaningful tests of normality (Snake River spring/ summer, Lower Columbia, and Puget Sound), the distribution of $\tilde{N}_{\mathrm{e}} / \tilde{N}_{\mathrm{T}}$ did not depart statistically from normal ( $P>0.10$ in all cases). Accordingly, we used the mean as a measure of central tendency and parametric statistics for these analyses. The distribution of $\tilde{N}_{\mathrm{e}} / \tilde{N}_{\mathrm{eH}}$, which (unlike $\tilde{N}_{\mathrm{e}} / \tilde{N}_{\mathrm{T}}$ ) is not constrained to the range $[0,1]$, has a long tail toward higher values and is not normally distributed (Kolmogorov-Smirnov test, $P<0.01$ ). Accordingly, we used the median as a measure of central tendency and nonparametric methods to test for significance. In evaluating correlations of $\tilde{N}_{\mathrm{e}} / \tilde{N}_{\mathrm{eH}}$ with various life history variables, we found comparable results with and without a log transformation to account for non- normality and hence report only the untransformed results.

Because we evaluated correlations of seven different variables in each life history type with both $\tilde{N}_{\mathrm{e}} / \tilde{N}_{\mathrm{T}}$ and $\tilde{N}_{\mathrm{e}} / \tilde{N}_{\mathrm{eH}}$, resulting in 28 statistical tests of the hypothesis that $r=0$, we also evaluated significance after correcting for multiple tests. Using the standard Bonferroni correction with a nominal $\alpha=0.05$, the test criterion becomes $P<0.05 / 28=0.00173$. Application of the less conservative, modified false discovery rate of Benjamini and Yekutieli (2001) produced the same results, so only the former method is presented.

The statistical analyses implicitly assume independence of data points, and we have good reason to believe this is true with respect to connectivity. With the exception of two localities in Puget Sound (Bridal Veil and Wallace), all our populations have been determined to be demographically independent using the criterion developed by McElhany et al. (2000) for recovery planning in Pacific salmon: migration is low enough that it does not appreciably affect extinction risk over 100 years. We can't rule out some correlations in abundance due to shared environmental conditions, but the populations are distributed over a large enough geographic area that we expect these effects to be relatively small.

Finally, as multigenerational $N_{\mathrm{e}} / N$ values are a function of single-generation ratios, it is also important to examine factors that determine $N_{\mathrm{e}}$ within individual generations. We did this by evaluating an estimator that Waples (2006) found provides a good estimate of singlegeneration $N_{\mathrm{e}}$ for some simulated data sets:

$$
\hat{N}_{\mathrm{e}} k \approx N_{\mathrm{T}}\left[\frac{1}{1+\mathrm{CV}^{2}\left(\bar{k}_{i}\right)}+\frac{\operatorname{Cov}\left(\bar{k}_{i}, N_{i}\right)}{2.5 \bar{k}_{*} \bar{N}_{i}}\right] .
$$

In this equation, $\bar{k}_{i}$ is the mean number of gametes contributed by each spawner in year $i\left(\bar{k}_{i}=2 \lambda_{i}\right.$ and hence is an analogue for population growth rate), $\bar{k}_{*}$ is the mean of the $\bar{k}_{i}$ across the years within a generation, and $\operatorname{Cov}\left(\bar{k}_{i}, N_{i}\right)$ is the covariance of $\bar{k}_{i}$ and $N_{i}$. The coefficient of variation of $\left(\bar{k}_{i}\right)$ is closely related to $\operatorname{CV}\left(\lambda_{i}\right)$ except that the former applies to a single generation whereas $\operatorname{CV}\left(\lambda_{i}\right)$ applies to the entire data series for each population. For each five-year generation in each population, we computed $\hat{N}_{\mathrm{e}} k$ and compared it with true $N_{\mathrm{e}}$ from Eq. 2. To evaluate factors that affect this estimator, we compared the true $N_{\mathrm{e}} / N_{\mathrm{T}}$ ratio each generation (Eqs. 1 and 2) with $\mathrm{CV}^{2}\left(\bar{k}_{i}\right)$ and the standardized covariance, $\operatorname{Cov}^{*}=\operatorname{Cov}\left(\bar{k}_{i}, N_{i}\right) / \bar{k}_{*} \bar{N}_{i}$.

\section{RESUlts}

\section{Reductions in $N_{\mathrm{e}}$ compared to census size}

Most single-generation $N_{\mathrm{e}} / N_{\mathrm{T}}$ values were in the range $0.7-0.9$ (Fig. 3A), indicating that $N_{\mathrm{e}}$ was reduced $\sim 10-30 \%$ compared to census size. Multigeneration $\tilde{N}_{\mathrm{e}} / \tilde{N}_{\mathrm{T}}$ was further reduced, to $\sim 0.5-0.7$ (Fig. 3B, Table 2; Appendix). Across all 56 populations, median $\tilde{N}_{\mathrm{e}} / \tilde{N}_{\mathrm{T}}$ (0.67) was significantly less than $1(95 \% \mathrm{CI}=0.60,0.72)$, 

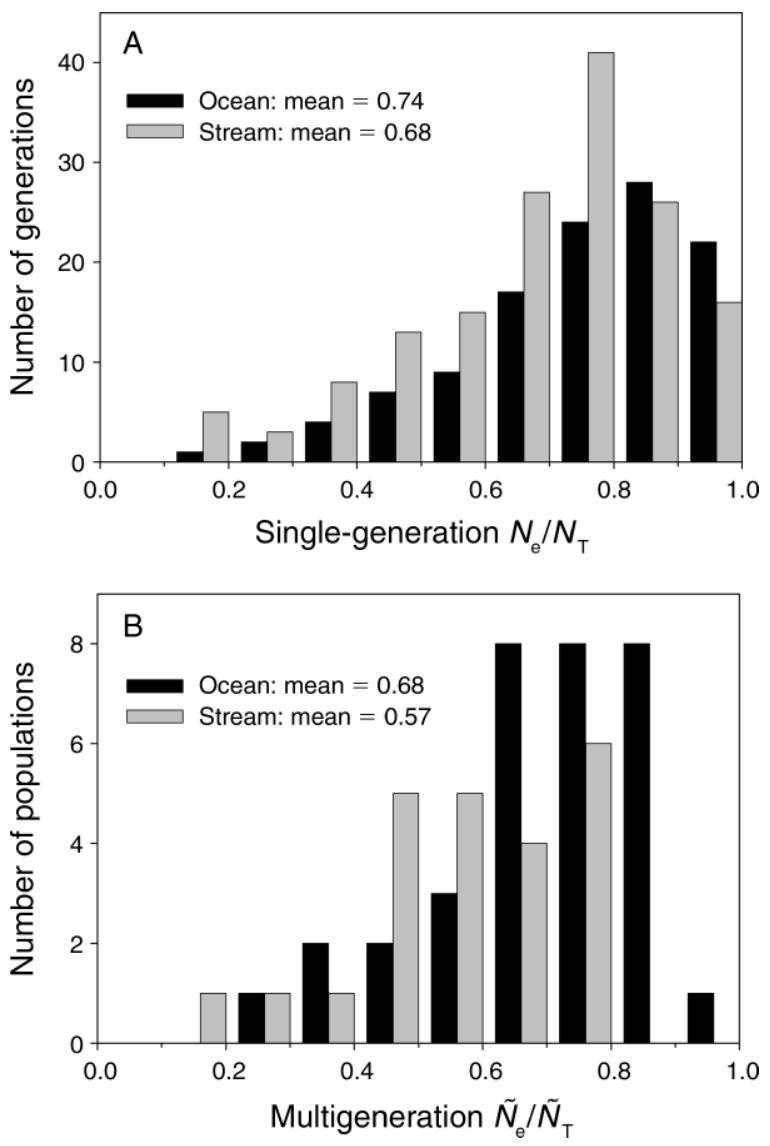

FIG. 3. Distribution of the ratio $N_{\mathrm{e}} / N_{\mathrm{T}}$ in two life history types of chinook salmon. $N_{\mathrm{T}}$ is the total number of spawners in a generation, and $N_{\mathrm{e}}$ is the effective population size, computed using Eq. 2. (A) Single-generation estimates. (B) Multigeneration estimates $\left(\tilde{N}_{\mathrm{e}} / \tilde{N}_{\mathrm{T}}\right)$ computed across all generations within each of 56 populations. and this was also true for both life history types (mean = 0.68 [range $=0.63-0.74]$ for ocean type and 0.57 [range $=$ 0.49-0.64] for stream type) and for each of the ESUs with sufficient numbers of populations for a test (Snake River spring/summer, Lower Columbia, and Puget Sound; all $P<0.001$ ). Although 95\% CIs slightly overlap for the two life history types, mean $\tilde{N}_{\mathrm{e}} / \tilde{N}_{\mathrm{T}}$ was significantly different $(t=2.59, \mathrm{df}=54, P=0.012)$.

Mean $\tilde{N}_{\mathrm{e}} / \tilde{N}_{\mathrm{T}}$ did not differ significantly among the three stream-type ESUs (one-way ANOVA, $F=1.00$, df $=2,20, P=0.39$ ). A highly significant difference was found among ocean-type ESUs (one-way ANOVA, $F=$ 12.43, df $=2,29, P<0.001$, after eliminating Southern Oregon, represented here by only a single population). A set of contrasts provides evidence that mean $\tilde{N}_{\mathrm{e}} / \tilde{N}_{\mathrm{T}}$ for the Lower Columbia ESU differs from that for Puget Sound and Interior Columbia ocean-type populations, which themselves do not differ (Lower Columbia vs. Interior Columbia and Puget Sound, $F=18.17$, df $=1$, 29, $P=0.0002$; Interior Columbia vs. Puget Sound, $F=$ 0.48 , df $=1,29, P=0.494)$. Mean $\tilde{N}_{\mathrm{e}} / \tilde{N}_{\mathrm{T}}$ was 0.56 in the Lower Columbia ESU and 0.80 in Interior Columbia and Puget Sound ESUs combined.

\section{Factors associated with reductions in $N_{\mathrm{e}}$}

Annual variation in population growth rate had the strongest influence on effective population size. The ratio $\tilde{N}_{\mathrm{e}} / \tilde{N}_{\mathrm{T}}$ was strongly (negatively) correlated with $\operatorname{CV}\left(\lambda_{i}\right)$ in both life history types (ocean type, $r=-0.80$; stream type, $r=-0.75$; both $P<0.001$; Table 3 , Fig. 4$)$. Linear regressions had slopes of -0.36 for ocean type, -0.38 for stream type, and -0.37 for all populations combined (Fig. 4). That is, for each unit increase in $\mathrm{CV}\left(\lambda_{i}\right), \tilde{N}_{\mathrm{e}} / \tilde{N}_{\mathrm{T}}$ was reduced by $\sim 0.37$. This pattern was nearly linear within the range of our data $\left(\operatorname{CV}\left(\lambda_{i}\right)=0.4\right.$ $\sim$ 2.2; Table 1, Fig. 4), but this linearity obviously cannot continue much further because $\tilde{N}_{\mathrm{e}} / \tilde{N}_{\mathrm{T}}$ is constrained to positive values.

TABLE 2. Summary of analyses of the ratio of effective population size $\left(N_{\mathrm{e}}\right)$ to the total number of spawners in a generation $\left(N_{\mathrm{T}}\right)$ and an estimate of $N_{\mathrm{e}}$ based on the harmonic mean method $\left(N_{\mathrm{eH}}\right)$ for chinook salmon in evolutionarily significant units (ESU).

\begin{tabular}{|c|c|c|c|c|c|}
\hline \multirow[b]{2}{*}{ ESU } & \multirow[b]{2}{*}{$n_{\mathrm{p}}$} & \multicolumn{2}{|c|}{$\tilde{N}_{\mathrm{e}} / \tilde{N}_{\mathrm{T}}$} & \multicolumn{2}{|c|}{$\tilde{N}_{\mathrm{e}} / \tilde{N}_{\mathrm{eH}}$} \\
\hline & & Mean & CI & Median & CI \\
\hline All data & 56 & $0.67 * * * \dagger$ & $0.60-0.72$ & $0.94^{*}$ & $0.90-1.01$ \\
\hline Ocean type & 33 & $0.68 * * *$ & $0.63-0.74$ & $0.93 * *$ & $0.84-0.96$ \\
\hline Puget Sound & 18 & $0.77 * * *$ & $0.72-0.81$ & $0.95^{*}$ & $0.91-0.98$ \\
\hline Lower Columbia & 12 & $0.56 * * *$ & $0.47-0.66$ & 0.81 & $0.71-1.06$ \\
\hline Interior Columbia & 2 & 0.83 & & 0.92 & \\
\hline Southern Oregon & 1 & 0.38 & & 0.44 & \\
\hline Stream type & 23 & $0.57 * * *$ & $0.49-0.64$ & 1.01 & $0.90-1.11$ \\
\hline Snake River & 16 & $0.55^{* * *}$ & $0.46-0.64$ & 1.03 & $0.90-1.22$ \\
\hline Mid-Columbia & 4 & $0.68 * *$ & $0.53-0.82$ & 1.04 & \\
\hline Upper Columbia & 3 & 0.52 & & 0.90 & \\
\hline
\end{tabular}

Notes: $N_{\mathrm{e}}$ is computed using Eq. 2 , and $N_{\mathrm{eH}}$ is computed using Eg. 3; the tilde ( $\sim$ ) indicates these are multigenerational ratios computed as harmonic means. CI is the $95 \%$ confidence interval for the mean or median, as indicated; $n_{\mathrm{p}}$ is the number of populations.

$\dagger$ Value for "All data" is a median.

* $P<0.05$; ** $P<0.01 ; * * * P<0.001$ for a one-tailed test that the ratio is $<1.0$. 
TABLE 3. Correlations between potential explanatory variables and the ratio of effective population size to the total number of spawners in a generation $\left(N_{\mathrm{e}} / N_{\mathrm{T}}\right)$ and the ratio of effective population size to an estimate of $N_{\mathrm{e}}$ based on the harmonic mean method $\left(N_{\mathrm{e}} / N_{\mathrm{eH}}\right)$ for chinook salmon.

\begin{tabular}{lrrlclll}
\hline \hline Life history & \multicolumn{1}{c}{$\bar{N}_{\mathrm{T}}$} & \multicolumn{1}{c}{$n$} & $\mathrm{CV}(N)$ & $\mathrm{GM}(\lambda)$ & $\mathrm{CV}(\lambda)$ & $g$ & $I$ \\
\hline Ocean type & & & & & & & \\
$\tilde{N}_{\mathrm{e}} / \tilde{N}_{\mathrm{T}}$ & 0.03 & 0.13 & $-\mathbf{0 . 6 2 * * *}$ & $0.41^{*}$ & $\mathbf{- 0 . 8 0 * * *}$ & 0.24 & -0.10 \\
$\tilde{N}_{\mathrm{e}} / \tilde{N}_{\mathrm{eH}}$ & -0.19 & -0.21 & 0.09 & $0.41^{*}$ & 0.21 & 0.04 & $-\mathbf{0 . 7 3 * * *}$ \\
Stream type & & & & & & & \\
$\tilde{N}_{\mathrm{e}} / \tilde{N}_{\mathrm{T}}$ & 0.04 & -0.05 & -0.39 & 0.13 & $\mathbf{- 0 . 7 5 * * *}$ & $-0.49^{*}$ & -0.23 \\
$\tilde{N}_{\mathrm{e}} / \tilde{N}_{\mathrm{eH}}$ & -0.25 & 0.28 & 0.03 & -0.20 & -0.16 & -0.17 & -0.05 \\
\hline
\end{tabular}

Notes: $N_{\mathrm{e}}$ is computed using Eq. 2, and $N_{\mathrm{eH}}$ is computed using Eq. 3; the tilde ( $\sim$ ) indicates these are multigenerational ratios computed as harmonic means. Coefficients that are statistically significant after correcting for multiple tests $(P<0.05 / 28=0.00179)$ are in boldface. Abbreviations are: $n$, number of years of data; $\lambda$, population growth rate; $C V$, coefficient of variation; GM, geometric mean; $g$, generation length; $I$, evenness age index. There were 33 populations in the ocean type and 23 populations in the stream type.

${ }^{*} P<0.05$; ** $P<0.01 ; * * * P<0.001$ for a two-tailed, unadjusted test that $r=0$.

Variation in $\lambda$ leads directly to variation in $N$, so it is not surprising that a similar (albeit weaker) negative correlation was also found between $\tilde{N}_{\mathrm{e}} / \tilde{N}_{\mathrm{T}}$ and $\mathrm{CV}(N)$ in both life history types (Table 3). However, after controlling for effects of $\mathrm{CV}\left(\lambda_{i}\right)$, the partial correlation between $\tilde{N}_{\mathrm{e}} / \tilde{N}_{\mathrm{T}}$ and $\mathrm{CV}\left(N_{i}\right)$ was small and not significant $(|r| \leq 0.24$ in both life history types). In contrast, after controlling for $\mathrm{CV}\left(N_{i}\right)$, the partial correlation between $\tilde{N}_{\mathrm{e}} / \tilde{N}_{\mathrm{T}}$ and $\mathrm{CV}\left(\lambda_{i}\right)$ remained strongly negative $(r=-0.70$ and -0.69 for stream- and ocean-type populations, respectively). Thus, most of the correlation between $\operatorname{CV}\left(\lambda_{i}\right)$ and $\tilde{N}_{\mathrm{e}} / \tilde{N}_{\mathrm{T}}$ was independent of $\mathrm{CV}\left(N_{i}\right)$, and annual variation in $N$ provided little additional information about $\tilde{N}_{\mathrm{e}} / \tilde{N}_{\mathrm{T}}$.

The ratio $\tilde{N}_{\mathrm{e}} / \tilde{N}_{\mathrm{T}}$ was not correlated with evenness age index $(I)$, mean population size $\left(\bar{N}_{\mathrm{T}}\right)$, or time series length $(n)$ in either life history type (Table 3 ). Two factors $\left(\operatorname{GM}\left(\lambda_{i}\right)\right.$ and generation length) showed significant correlations in only one life history type, but these were not significant after correcting for multiple tests (Table 3). The general importance of these factors in shaping $N_{\mathrm{e}} / N$ ratios might warrant further evaluation with independent data from additional populations.

Our evaluations of single-generation effective : census size ratios found similar patterns in both life history types: a strong, negative correlation between $N_{\mathrm{e}} / N_{\mathrm{T}}$ and $\mathrm{CV}^{2}\left(\bar{k}_{i}\right)$ (stream type, $r=-0.64$; ocean type, $r=-0.65$ ) and an even stronger, positive correlation between $N_{\mathrm{e}} / N_{\mathrm{T}}$ and Cov* (stream type, $r=0.76$; ocean type, $r$ $=0.85$; all $P<0.001$ ). These results show that, within individual generations, effective size is reduced the most when (1) annual variation in productivity is high and (2) $\lambda_{i}$ and $N_{i}$ are negatively correlated (i.e., mean productivity is higher in years with a low number of breeders and vice versa).

$$
\hat{N}_{\mathrm{eH}} \text { as a proxy for } N_{\mathrm{e}}
$$

A priori, if the harmonic mean method is a good proxy for true effective size, we expect that geometric mean $N_{\mathrm{e}} / \hat{N}_{\mathrm{eH}} \approx 1$, with a distribution skewed toward large values since this ratio has an upper bound of infinity. Empirical distributions of single-generation $N_{\mathrm{e}} / \hat{N}_{\mathrm{eH}}$ (Fig. 5A) and multigeneration $\tilde{N}_{\mathrm{e}} / \tilde{N}_{\mathrm{eH}}$ (Fig. 5B) both generally reflect the expected pattern. For all populations, a signed-rank test provides some evidence that median $\tilde{N}_{\mathrm{e}} / \tilde{N}_{\mathrm{eH}}<1(S=-251, P=0.040)$; however, the $95 \% \mathrm{CI}$ includes 1: median $=0.94(0.90,1.01)($ Table 1). Median $\tilde{N}_{\mathrm{e}} / \tilde{N}_{\mathrm{eH}}$ was $0.93(0.84,0.96)$ for ocean-type populations and $1.01(0.90,1.11)$ for stream type. Although the median for ocean type was significantly less than $1(S=$ $-151.5, P<0.01)$, the difference between the two life history types was not significant (median two-sample test, $S=13, P>0.58)$. In Puget Sound, median $\tilde{N}_{\mathrm{e}} / \tilde{N}_{\mathrm{eH}}$ (0.95) was less than $1(S=-46.5, P<0.05)$, but CIs included 1 for the other two ESUs with sufficient data (Lower Columbia and Snake River; Table 1). A one-way

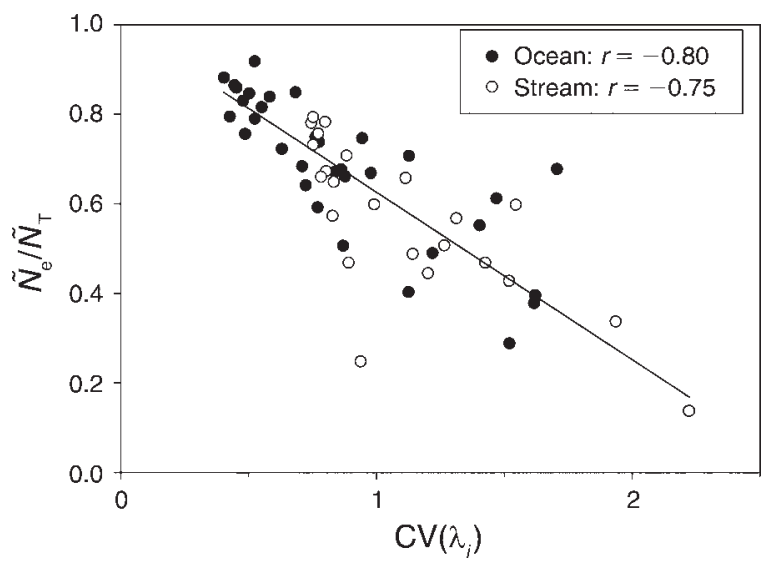

FIG. 4. Relationship between the multigeneration ratio of effective population size to the total number of spawners in a generation, $\tilde{N}_{\mathrm{e}} / \tilde{N}_{\mathrm{T}}$, and the coefficient of variation of annual productivity, $\operatorname{CV}\left(\lambda_{i}\right)$, where $\lambda_{i}$ is the population growth rate. Each data point represents a single population, distinguished by life history type. The solid line shows the linear regression (slope $=-0.37$ ) between the two variables for all data points, forced through the point $\operatorname{CV}\left(\lambda_{i}\right)=0, \tilde{N}_{\mathrm{e}} / \tilde{N}_{\mathrm{T}}=1$. 

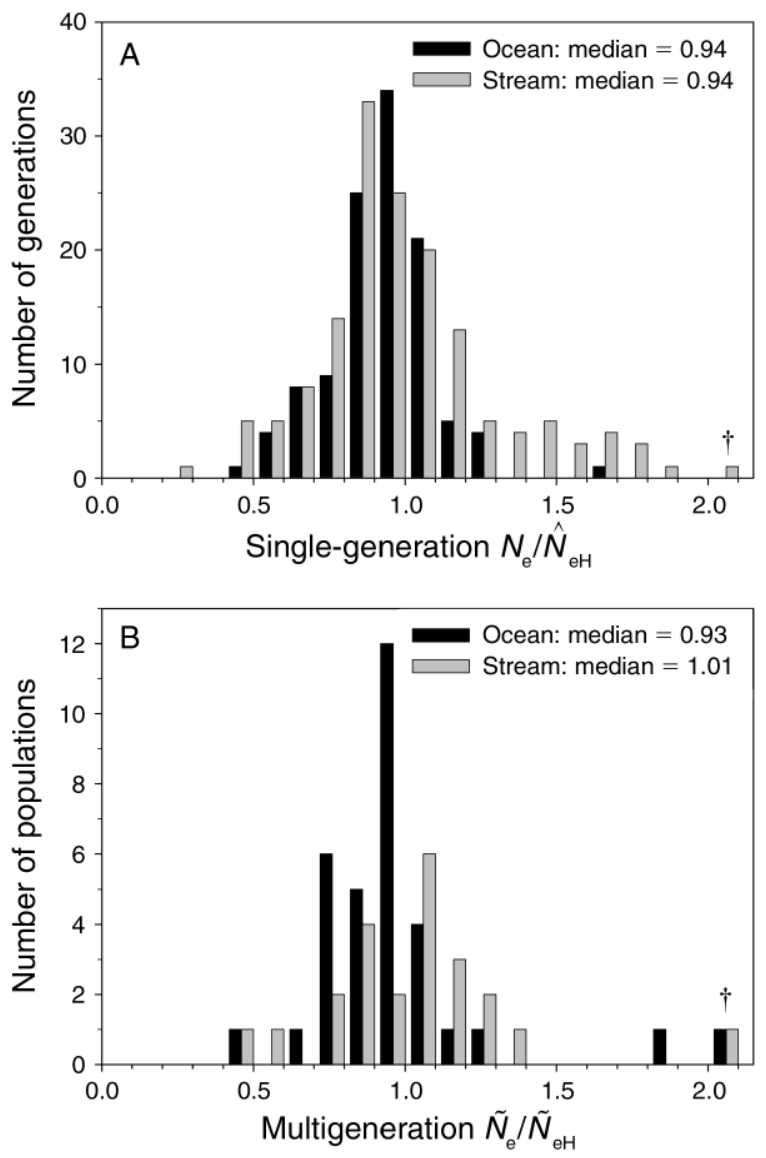

FIG. 5. Distribution of the ratio of the effective population size $\left(N_{\mathrm{e}}\right)$ to an estimate of $N_{\mathrm{e}}$ based on the harmonic mean method $\left(N_{\mathrm{eH}}\right)$ in two life history types of chinook salmon. $N_{\mathrm{e}}$ is computed using Eq. 2, and $N_{\mathrm{eH}}$ is computed using Eq. 3. (A) Single-generation estimates $\left(N_{\mathrm{e}} / \hat{N}_{\mathrm{eH}}\right)$ and (B) multigeneration estimates $\left(\tilde{N}_{\mathrm{e}} / \tilde{N}_{\mathrm{eH}}\right)$ were computed across all generations within each of 56 populations. The bins marked with a dagger include all values with $N_{\mathrm{e}} / \hat{N}_{\mathrm{eH}}>2.0$.

median test found no evidence that $\tilde{N}_{\mathrm{e}} / \tilde{N}_{\mathrm{eH}}$ differs among ESUs in either life history type (ocean type, $\chi^{2}=3.10, P=$ 0.38 ; stream type, $\chi^{2}=3.07, P=0.22$ ).

Because of the nonnormality of $\tilde{N}_{\mathrm{e}} / \tilde{N}_{\mathrm{eH}}$, we evaluated effects of outliers, which we defined as populations for which $\tilde{N}_{\mathrm{e}}$ and $\tilde{N}_{\mathrm{eH}}$ differed by a factor of two or more (i.e., $\tilde{N}_{\mathrm{e}} / \tilde{N}_{\mathrm{eH}} \leq 0.5$ or $\tilde{N}_{\mathrm{e}} / \tilde{N}_{\mathrm{eH}} \geq 2$ ). Four populations met this criterion: North Fork Nooksack (2.90; Puget Sound ESU), Upper Grande Ronde (2.45) and Valley Creek (0.49) (both Snake River ESU), and Rogue River (0.44; Southern Oregon ESU). Removing these populations did not materially affect results. Examination of spawner-recruit data suggests possible explanations for most outliers. High $\tilde{N}_{\mathrm{e}} / \tilde{N}_{\mathrm{eH}}$ values were strongly affected by very low $N_{i}$ in a single year $\left(N_{i}=10\right.$ in 1990 in North Fork Nooksack; $N_{i}=3$ in 1989 in Upper Grande Ronde). In the Rogue River, every year had at least 1000 spawners (so $\hat{N}_{\mathrm{eH}}$ remained fairly large), but $N_{\mathrm{e}}$ was reduced by unusually high variability in population growth rate $\left(\mathrm{CV}\left(\lambda_{i}\right)=1.62\right.$; Table 1$)$.

To quantitatively evaluate performance of singlegeneration estimators of $N_{\mathrm{e}}$, for each five-year generation we calculated $\hat{N}_{\mathrm{eH}}$ (from Eq. 3 ) and $\hat{N}_{\mathrm{e}} k$ (from Eq. 4) and compared results with the "true" effective size, $N_{\mathrm{e}}$ (Eq. 2). We calculated the mean squared error (MSE) as the mean of $d_{j}^{2}$, the squared difference between $\hat{N}_{\mathrm{ej}}$ and $N_{\mathrm{e} j}$. For both stream-type and ocean-type life histories, the MSE for $\hat{N}_{\mathrm{e}} k$ was more than twice as large as the MSE for $\hat{N}_{\mathrm{eH}}$. Therefore, $\hat{N}_{\mathrm{eH}}$ is a better proxy for singlegeneration $N_{\mathrm{e}}$ than $\hat{N}_{\mathrm{e}} k$ and is much simpler to calculate.

\section{Factors affecting performance of $\hat{N}_{\mathrm{eH}}$}

In both life history types, $\tilde{N}_{\mathrm{e}} / \tilde{N}_{\mathrm{eH}}$ showed no significant relationship with $\mathrm{CV}\left(\lambda_{i}\right), \mathrm{CV}(N)$, mean population size $\left(\bar{N}_{\mathrm{T}}\right)$, or length of data series $(n)$ (Table 3). A positive association between $\tilde{N}_{\mathrm{e}} / \tilde{N}_{\mathrm{eH}}$ and $\operatorname{GM}\left(\lambda_{i}\right)$ was found in ocean-type populations but was not significant after accounting for multiple tests (Table 3). In ocean-type populations, we found a negative correlation between $\tilde{N}_{\mathrm{e}} / \tilde{\mathrm{N}}_{\mathrm{eH}}$ and evenness age index $(I)$; this remained significant after correction for multiple testing but not after removal of the two outlier populations.

Single-generation $N_{\mathrm{e}} / \hat{N}_{\mathrm{eH}}$ showed no relationship with $\mathrm{CV}^{2}\left(\bar{k}_{i}\right)$ or $\mathrm{Cov}^{*}$ in either life history type. Because $N_{\mathrm{e}} / N_{\mathrm{T}}$ was strongly influenced by both variables, we interpret this result to mean that effects of $\mathrm{CV}^{2}\left(\bar{k}_{i}\right)$ and Cov* on $\hat{N}_{\mathrm{eH}}$ were similar to those for $N_{\mathrm{e}}$.

\section{Discussion}

Data for chinook salmon provide strong empirical support for predictions based on recent theoretical and numerical studies: that variability in a key ecological parameter (population growth rate) can strongly influence a key evolutionary parameter (effective population size). Most previous demographic evaluations of $N_{\mathrm{e}}$ and the $N_{\mathrm{e}} / N$ ratio have focused on factors (uneven sex ratio and greater-than-random variation in reproductive success) that reduce effective size for individuals that mate in a given season. If the species has discrete generations, the result can be interpreted as effective size per generation $\left(N_{\mathrm{e}}\right)$; if the species has overlapping generations, the result can be interpreted as the effective number of breeders $\left(N_{\mathrm{b}}\right)$ in a particular year. In semelparous species with variable age at maturity, the offspring produced each year represent the lifetime reproductive output of a group of parents, and an additional factor, annual variation in productivity (population growth rate), becomes important to consider because it increases the variance in reproductive success among individuals across a generation. We first review some of the major quantitative results before commenting on more general implications.

\section{Magnitude of reductions in $N_{\mathrm{e}}$}

Across all 56 populations, mean multigenerational $\tilde{N}_{\mathrm{e}} / \tilde{N}_{\mathrm{T}}$ was 0.64 (median 0.67), indicating that the level of 
annual variation in $\lambda$ seen in chinook salmon populations reduces their effective population size by an average of $\sim 35 \%$. Reductions in $N_{\mathrm{e}}$ were significantly greater for stream-type populations (mean $\tilde{N}_{\mathrm{e}} / \tilde{N}_{\mathrm{T}}=0.57$; $87 \%$ of populations with values in the range $0.4-0.8$; Fig. 3B) than for ocean-type populations (mean $=0.68$; $82 \%$ in the range $0.5-0.9$ ). These results reinforce and expand considerably preliminary conclusions by Waples (2002), who estimated $\tilde{N}_{\mathrm{e}} / \tilde{N}_{\mathrm{T}}$ to be $\sim 0.4-0.6$ for a single population of stream-type chinook salmon (Marsh Creek, based on a slightly shorter time series than used here).

To focus on genetic consequences of annual variation in population demography, our analyses have ignored deviations from ideal populations within years and implicitly assumed that $N_{b(i)} / N_{i}=1$ each year. A comprehensive evaluation of effective population size should consider both factors: those that operate among individuals within years and those that operate among years within a generation. The two types of reductions are multiplicative (Waples 2002). Previous studies show that most estimates of $N_{b(i)} / N_{i}$ in natural populations of chinook salmon fall in the range 0.1-0.4 (Shrimpton and Heath 2003, Waples 2004). When these estimates are combined with those reported here, we arrive at the following comprehensive estimates for chinook salmon: $\hat{N}_{\mathrm{e}} / \hat{N} \sim 0.04-0.32$ for stream type and $\sim 0.05-0.36$ for ocean type. This means, for example, that a typical population of stream-type chinook salmon with a total of 1000 spawners per generation would experience the same rate of genetic drift as a truly ideal population with only 40-320 spawners. The practical consequences are substantial: a population with $N_{\mathrm{e}}=320$ loses genetic variability over three times as fast as one with $N_{\mathrm{e}}=1000$, and the rate of loss is 25 times as high if $N_{\mathrm{e}}$ is only 40.

In a review of published estimates (Frankham 1995), the mean single-generation $N_{\mathrm{e}} / N$ (accounting for sex ratio differences and variance in reproductive success) was 0.35 . Our data suggest that this would be an upper bound to the $N_{\mathrm{e}} / N$ ratio in chinook salmon. Frankham did find a lower mean value $(0.11)$ in studies that also accounted for variation in population size across generations, but this result was obtained by dividing the harmonic mean $N_{\mathrm{e}}$ by the arithmetic mean $N$, which will bias the multigenerational value downwards even if single-generation $N_{\mathrm{e}} / N$ remains constant (Kalinowski and Waples 2002). In contrast, the method used here to compute multigenerational $\tilde{N}_{\mathrm{e}} / \tilde{N}_{\mathrm{T}}$ uses harmonic means for both numerator and denominator, so the multigenerational value is a direct function of single-generation values. Thus, our data suggest that $N_{\mathrm{e}} / N$ in most chinook salmon populations is lower than mean values reported for other species.

\section{Factors influencing the magnitude of reduction in $N_{\mathrm{e}}$}

Previous studies using simulated data showed that high variance of $\lambda_{i}$ was associated with high rates of allele frequency change (Waples 2002) and rapid increases in inbreeding (Waples 2006). Our results are in accord with these previous findings: of the variables we considered, $\tilde{N}_{\mathrm{e}} / \tilde{N}_{\mathrm{T}}$ was most strongly (and negatively) correlated with $\operatorname{CV}\left(\lambda_{i}\right)$ (Fig. 4, Table 3). By itself, $\operatorname{CV}\left(\lambda_{i}\right)$ explained $58 \%$ of the variance in the multigenerational $\tilde{N}_{\mathrm{e}} / \tilde{N}_{\mathrm{T}}$ for stream-type populations and almost two-thirds of the variance for ocean-type populations. In both life histories, high interannual variation in $\lambda_{i}$ had a strong association with large reductions in effective population size.

Variability in $\lambda_{i}$ explains much of the difference in mean $\tilde{N}_{\mathrm{e}} / \tilde{N}_{\mathrm{T}}$ between the two life history types. This difference is driven by data for three ESUs that collectively hold 46 of the 56 populations (Table 2). Relatively low mean values of $\tilde{N}_{\mathrm{e}} / \tilde{N}_{\mathrm{T}}$ were found in Snake River spring/summer (0.55) and Lower Columbia River (0.56) ESUs compared to Puget Sound (0.77). The former two ESUs had relatively high mean $\operatorname{CV}\left(\lambda_{i}\right)(1.19$ for Snake River spring/summer; 1.04 for Lower Columbia) compared to Puget Sound (0.71). Thus, the difference in mean $\tilde{N}_{\mathrm{e}} / \tilde{N}_{\mathrm{T}}$ between stream- and oceantype populations can be attributed more to the relatively low variance in population growth rate found in one ocean-type ESU (Puget Sound) than to consistent differences between the major life history types. In contrast to the rather uniform juvenile and adult life histories of Interior Columbia stream-type populations (Waples et al. 2004), the "ocean-type" life history is actually quite diverse and encompasses a wide range of juvenile and adult patterns (Beckman 2002, Greene and Beechie 2004). Ocean-type populations are also more heterogeneous than stream-type populations in $\tilde{N}_{\mathrm{e}} / \tilde{N}_{\mathrm{T}}$, with means within ESUs ranging from 0.38 to 0.83 (Table 2). The two extreme values are for ESUs with only one and two populations, respectively, and hence must be interpreted with caution. Nevertheless, collectively these results suggest that local ecological and environmental factors that influence the magnitude of annual demographic fluctuations might be more important than the stream-type/ocean-type dichotomy in determining the $N_{\mathrm{e}} / N$ ratio in chinook salmon.

Our empirical data show that $\tilde{N}_{\mathrm{e}} / \tilde{N}_{\mathrm{T}}$ was reduced most in generations with an inverse correlation between $\lambda_{i}$ and $N_{i}$, that is, when low numbers of spawners were associated with high population growth rates (and vice versa). This is important because the idea that population density affects $\lambda$ is a fundamental principle in ecology and fishery biology. If density-dependent compensation promotes high growth rates at low abundance, populations will tend to rebound quickly from depressed levels, which promotes stability and increases viability. But this comes at some evolutionary cost: when a small number of parents contribute a large fraction of genes to the next generation, effective population size is reduced, leading to higher rates of inbreeding, more rapid loss of genetic variation, and reduced efficiency of natural selection. 
Although this eco-evolutionary trade-off has direct relevance to both theoretical and applied ecology, it has received little attention in the literature. However, an interesting and related effect was recently discussed by Pertoldi et al. (2007). Basic ecological theory (e.g., Taylor 1961) predicts that as population size increases, variance in $N$ also increases at a moderate rate, described by a variance-mean scaling factor $\beta$. If the variance increases unusually fast with increasing $N$ (large $\beta$ ), harmonic mean $N$ can decrease even when the arithmetic mean $N$ increases. Long-term effective size is a function of harmonic mean $N_{\mathrm{e}}$, so evolutionary processes could be compromised in a population with high variance in $N$, even as mean abundance increases. A higher mean $N$ generally reduces demographic stochasticity and associated risks, so this suggests a trade-off between ecological and genetic risks that has some similarities to that described here. However, there are some important differences as well. First, the tradeoff we describe applies to correlations between population size and productivity among years within a generation, whereas the phenomenon described by Pertoldi et al. (2007) arises from variation in $N$ and $N_{\mathrm{e}}$ across multiple generations. Second, the variance-mean scaling effect leads to implicit trade-offs even if only demographic factors are considered, since most population viability models depend heavily on the variance as well as the mean of population size and growth rate (Beissenger and McCullough 2002, Morris and Doak 2002). Nevertheless, these two related (and only recently described) phenomena suggest that it could be profitable to more closely examine the genetic/evolutionary consequences of population dynamic processes, as ecoevolutionary trade-offs might be more prevalent than has been appreciated to date.

$$
\hat{N}_{\mathrm{eH}} \text { as a proxy for } \mathrm{N}_{e}
$$

Across all populations, median $\tilde{N}_{\mathrm{e}} / \tilde{N}_{\mathrm{eH}}(0.94)$ was less than 1, indicating that $\hat{N}_{\mathrm{eH}}$ has a slight tendency to overestimate true $N_{\mathrm{e}}$. This pattern, also observed in simulated data (Waples 2002, 2006), is attributable to ocean-type populations, as median $\tilde{N}_{\mathrm{e}} / \tilde{N}_{\mathrm{eH}}$ for steamtype populations was 1.01 (Table 2). In both life history types, two-thirds of the populations have multigeneration $\hat{N}_{\mathrm{eH}}$ within $20 \%$ of $\tilde{N}_{\mathrm{e}}$. None of the population-level factors we considered had much influence on multigenerational $\tilde{N}_{\mathrm{e}} / \tilde{N}_{\mathrm{eH}}$, presumably because they had similar effects on both the numerator and the denominator of this ratio. This suggests that $\tilde{N}_{\mathrm{eH}}$ might be a reasonable proxy for true $N_{\mathrm{e}}$ for a wide range of conditions, at least in chinook salmon and species with similar life history traits. Although Eq. 4 is useful heuristically for identifying the relationship between single-generation $N_{\mathrm{e}} / N$ and the covariance of $N_{i}$ and population growth rate, we found that the estimator $\hat{N}_{\mathrm{e}} k$ did not perform as well as $\hat{N}_{\mathrm{eH}}$.

\section{Relevance to other species}

Three major factors will determine how important the phenomena discussed here are for other species. First, semelparous species should be most strongly affected, because their lifetime genetic contribution results from a single season of reproduction. In iteroparous species, reproductive output is integrated across multiple years, which should at least partially buffer effects of variation in mean reproductive success in individual years. However, these effects are likely to be important in any species that experience highly variable recruitment success, environmentally driven recruitment, or other boom-and-bust cycles, including plants such as pinyon pine (Chambers et al. 1999), desert annuals (Venable 2007), and many marine organisms, such as krill (Brierley and Reid 1999).

Second, variation in age at maturity is necessary; otherwise, all individuals within a generation are characterized by the same mean reproductive success. Notably, many species subject to boom-and-bust cycles also exhibit variable age at maturity. Diapausing zooplankters, (e.g., Daphnia spp. [Caceres and Tessier 2004], copepods [Hairston and Munns 1984], and fairy shrimp [Bohonak and Whiteman 1999]) are prime examples, as are desert annuals with seeds that germinate in years with higher-than-average rainfall. Other species, including plants (Shem-Tov et al. 2002), sponges (Harrison 1974), stoneflies (Zwick 1996), and rotifers (Pourriot and Snell 1983), maintain variable age at maturity by maintaining a seed or germ bank as an apparent bet-hedging strategy against catastrophes (Evans and Dennehy 2005).

Finally, for this phenomenon to be important there must be tight coupling between variation in $N$ and variation in $\lambda$. This coupling does not occur in all semelparous species; the key is whether density-dependent population regulation occurs in a way that affects individual cohorts as a unit (Waples 2006). In annual plants with seed banks, for example, population size of mature individuals can vary dramatically from year to year, depending upon the number of suitable sites for germination (Nunney 2002). However, the crop of seedlings drawn from the seed bank is produced by parents in many previous years; therefore, a boom-orbust year for germination will affect the lifetime reproductive success of individuals that flowered in several different prior years. This serves to dampen extreme fluctuations in productivity across years and helps to minimize reductions in $N_{\mathrm{e}}$. In Pacific salmon, in contrast, the primary factors that determine population size often act on single cohorts, in either freshwater rearing environments or early stages of marine life. Under these conditions, mean reproductive success of breeders in a particular year can be strongly influenced by events in a single subsequent year, leading to a high variance in $\lambda$ and reductions in $N_{\mathrm{e}}$. Interestingly, from the perspective of population regulation, monocarpic perennials that produce vegetative rosettes that flower at 
a variety of ages (such as the century plant, Agave americana) are more similar to Pacific salmon than they are to annuals with seed banks. Monocarpic perennials that successfully germinate in a given year represent the entire reproductive output of the plants that flowered (and died) the previous year (Metcalf et al. 2003). In these species, therefore (as in Pacific salmon), conditions that favor unusually high or low germination rates in a given year directly affect the lifetime reproductive success of an entire year of breeders, which are functionally equivalent to a group of mixed-age Pacific salmon that spawn and die in a particular year.

More broadly, results presented here lend support to the emerging idea that many key issues in population ecology and conservation are eco-evolutionary in nature and require joint consideration of ecological and evolutionary processes. If we accept the argument of Kinnison and Hairston (2007:444) that "population persistence through space and time depends on ecoevolutionary dynamics that arise through interactions of evolution, its fitness consequences and population abundance," it follows that these factors should be considered jointly in management activities such as establishing minimum viable population sizes, setting targets for harvest, and designing captive breeding or translocation programs. Data presented here document an evolutionary effect that can increase risks to populations but would not be detected from analysis only of population abundance data. It seems likely that similar eco-evolutionary interactions or trade-offs affect more species than has been appreciated to date.

\section{ACKNOWLedgments}

We thank Rich Zabel, Mark Scheuerell, Tom Reed, Correigh Greene, and two anonymous reviewers for insightful comments on an earlier draft, Kathleen Neely and David Teel for help with Figs. 1 and 2, and Jim Faulkner for statistical advice.

\section{Literature Cited}

Allendorf, F. W., and G. Luikart. 2007. Conservation and the genetics of populations. Blackwell, Oxford, UK.

Bacaer, N., and R. Ouifki. 2007. Growth rate and basic reproduction number for population models with a simple periodic factor. Mathematical Biosciences 210:647-658.

Beamesderfer, R. C. P., H. A. Schaller, M. P. Zimmerman, C. E. Petrosky, O. P. Langness, and L. LaVoy. 1998. Spawner-recruit data for spring and summer Chinook salmon populations in Idaho, Oregon, and Washington. Pages 1-78 in D. R. Marmorek and C. N. Peters, editors. Plan for analyzing and testing hypotheses (PATH): retrospective and prospective analyses of spring/summer chinook reviewed in FY 1997. ESSA Technologies, Vancouver, British Columbia, Canada.

Beckman, B. R. 2002. Growth and the plasticity of smolting in Chinook salmon. Dissertation. University of Washington, Seattle, Washington, USA.

Beissinger, S. R., and D. R. McCullough, editors. 2002. Population viability analysis. University of Chicago Press, Chicago, Illinois, USA.

Benjamini, Y., and D. Yekutieli. 2001. The control of false discovery rate under dependency. Annals of Statistics 29: 1165-1188.

Bohonak, A. J., and H. H. Whiteman. 1999. Dispersal of the fairy shrimp Branchinecta coloradensis (Anostraca): effects of hydroperiod and salamanders. Limnology and Oceanography 44:487-493.

Boyce, M. S., C. V. Haridas, and C. T. Lee. and the NCEAS Stochastic Demography Working Group. 2006. Demography in an increasingly variable world. Trends in Ecology and Evolution 21:141-148.

Brierley, A., and K. Reid. 1999. Kingdom of the krill: the boom and bust cycle of a tiny crustacean holds the key to the health of the Southern Ocean. New Scientist 162:36-41.

Caceres, C. E., and A. J. Tessier. 2004. To sink or swim: variable diapause strategies among Daphnia species. Limnology and Oceanography 49:1333-1340.

Cavalli-Sforza, L. L., and A. W. F. Edwards. 1967. Phylogenetic analysis: models and estimation procedures. Evolution 21:550-570.

Chambers, J. C., S. B. Vander Wall, and E. W. Schupp. 1999. Seed and seedling ecology of pinon and juniper species in the pygmy woodlands of western North America. Botanical Review 65:1-38.

Evans, M. E. K., and J. J. Dennehy. 2005. Germ banking: bethedging and variable release from egg and seed dormancy. Quarterly Review of Biology 80:431-451.

Felsenstein, J. 1976. The theoretical population genetics of variable selection and migration. Annual Review of Genetics 10:253-280.

Frankham, R. 1995. Effective population size/adult population size ratios in wildlife: a review. Genetical Research 66:95107.

Good, T. P., R. S. Waples, and P. Adams, editors. 2005. Updated status of federally listed ESUs of West Coast salmon and steelhead. Technical Memo NMFS-NWFSC-66. U.S. Department of Commerce, National Oceanic and Atmospheric Administration, Washington, D.C., USA.

Greene, C. M., and T. J. Beechie. 2004. Consequences of potential density-dependent mechanisms on recovery of ocean-type Chinook salmon (Oncorhynchus tshawytscha). Canadian Journal of Fisheries and Aquatic Sciences 61: $590-602$.

Hahn, G. J., and W. Q. Meeker. 1991. Statistical intervals: a guide for practitioners. John Wiley, New York, New York, USA.

Hairston, N. G., and W. R. Munns. 1984. The timing of copepod diapause as an evolutionarily stable strategy. American Naturalist 123:733-751.

Harrison, F. 1974. The localization of nuclease activity in spongiilid gemmules by substrate film enzymology. Acta Histochemica 51:157-163.

Healey, M. C. 1991. Life history of Chinook salmon (Oncorhynchus tshawytscha). Pages 311-393 in C. Groot and L. Margolis, editors. Pacific salmon life histories. University of British Columbia Press, Vancouver, British Columbia, Canada.

Healey, M. C., and W. R. Heard. 1984. Inter- and intrapopulation variation in the fecundity of Chinook salmon (Oncorhynchus tshawytscha) and its relevance to life history theory. Canadian Journal of Fisheries and Aquatic Sciences 41:476-483.

Hedrick, P. 2005. Large variance in reproductive success and the $N_{e} / N$ ratio. Evolution 59:1596-1599.

Hone, J., and T. H. Clutton-Brock. 2007. Climate, food, density and wildlife population growth rate. Journal of Animal Ecology 76:361-367.

Hooper, H. L., R. Connon, A. Callaghan, G. Fryer, S. Yarwood-Buchanan, J. Biggs, S. J. Maund, T. H. Hutchinson, and R. M. Sibly. 2008. The ecological niche of Daphnia magna characterized using population growth rate. Ecology 89:1015-1022.

Jones, J., P. J. Doran, and R. T. Holmes. 2007. Spatial scaling of avian population dynamics: population abundance, growth rate, and variability. Ecology 88:2505-2515. 
Kalinowski, S. T., and R. S. Waples. 2002. Relationship of effective to census size in fluctuating populations. Conservation Biology 16:129-136.

Kimura, M. 1983. The neutral theory of molecular evolution. Cambridge University Press, New York, New York, USA.

Kinnison, M. T., and N. G. Hairston, Jr. 2007. Ecoevolutionary conservation biology: contemporary evolution and the dynamics of persistence. Functional Ecology 21:444454.

Kitamura, K., and T. Kawahara. 2009. Clonal identification by microsatellite loci in sporadic flowering of a dwarf bamboo species, Sasa cernua. Journal of Plant Research 122:299-304.

McElhany, P., M. H. Ruckelshaus, M. J. Ford, T. C. Wainwright, and E. P. Bjorkstedt. 2000. Viable salmonid populations and the recovery of evolutionarily significant units. Technical Memorandum NMFS-NWFSC 42. U.S. Department of Commerce, National Oceanic and Atmospheric Administration, Washington, D.C., USA.

Metcalf, J. C., K. E. Rose, and M. Rees. 2003. Evolutionary demography of monocarpic perennials. Trends in Ecology and Evolution 18:471-480.

Morris, W. F., and D. F. Doak. 2002. Quantitative conservation biology: the theory and practice of population viability analysis. Sinauer, Sunderland, Massachusetts, USA.

Nobel, P. S. 1992. Annual variations in flowering percentage, seedling establishment, and ramet production for a desert perennial. International Journal of Plant Sciences 153:102107.

Nunney, L. 2002. The effective size of annual plant populations: the interaction of a seed bank with fluctuating population size in maintaining genetic variation. American Naturalist 160:195-204.

Paulsen, C. M., R. A. Hinrichsen, and T. R. Fisher. 2007. Measure twice, estimate once: Pacific salmon population viability analysis for highly variable populations. Transactions of the American Fisheries Society 136:346-364.

Pertoldi, C., L. A. Bach, J. S. F. Barker, P. Lundberg, and V. Loeschcke. 2007. The consequences of the variance-mean rescaling effect on effective population size. Oikos 116:769774.

Peterman, R. M. 1981. Form of random variation in salmon smolt-adult relations and its influence on production estimates. Canadian Journal of Fisheries and Aquatic Sciences 38:1113-1119.

Peters, C., et al. 1999. PATH decision analysis report for Snake River fall Chinook. ESSA Technologies, Vancouver, British Columbia, Canada. 〈http://www.efw.bpa.gov/PATH/reports/ 991006.fall99d6.pdf $\rangle$

Pourriot, R., and T. Snell. 1983. Resting eggs in rotifers. Hydrobiologia 104:213-224.

Seamans, M. E., and R. J. Gutierrez. 2007. Sources of variability in spotted owl population growth rate: testing predictions using long-term mark-recapture data. Oecologia 152:57-70.
Shem-Tov, S., E. Zaady, and Y. Gutterman. 2002. Germination of Carrichtera annua (Brassicaceae) seeds on soil samples collected along a rainfall gradient in the Negev Desert of Israel. Israel Journal of Plant Science 50:113-118.

Shrimpton, J. M., and D. D. Heath. 2003. Temporal changes in genetic diversity and effective population size in chinook salmon (Oncorhynchus tshawytscha) populations: large versus small scale perturbation effects. Molecular Ecology 12:25712583.

Taylor, L. R. 1961. Aggregation, variance and the mean. Nature 189:732-735.

Van der Voort, M. E., and J. B. McGraw. 2006. Effects of harvester behavior on population growth rate affects sustainability of ginseng trade. Biological Conservation 130: 505-516.

Venable, D. L. 2007. Bet hedging in a guild of desert annuals. Ecology 88:1086-1090.

Vitalis, R., S. Glémin, and I. Olivieri. 2004. When genes go to sleep: the population genetic consequences of seed dormancy and monocarpic perenniality. American Naturalist 163:295311.

Waples, R. S. 1991. Pacific salmon, Oncorhynchus spp., and the definition of "species" under the Endangered Species Act. Marine Fisheries Review 53(3):11-22.

Waples, R. S. 2002. The effective size of fluctuating salmon populations. Genetics 161:783-791.

Waples, R. S. 2004. Salmonid insights into effective population size. Pages 295-314 in A. P. Hendry and S. C. Stearns, editors. Evolution illuminated: salmon and their relatives. Oxford University Press, Oxford, UK.

Waples, R. S. 2006. Seed banks, salmon, and sleeping genes: effective population size in semelparous, age-structured species with fluctuating abundance. American Naturalist 167:118-135.

Waples, R. S., D. J. Teel, J. Myers, and A. Marshall. 2004. Life history divergence in chinook salmon: historic contingency and parallel evolution. Evolution 58:386-403.

Whisler, J., and S. Jacobs. 2001. Prediction of 2001 ocean abundance of Rogue River fall Chinook salmon. Oregon Department of Fish and Wildlife, Corvallis, Oregon, USA.

Wisdom, M. J., L. S. Mills, and D. F. Doak. 2000. Life stage simulation analysis: estimating vital-rate effects on population growth for conservation. Ecology 81:628-641.

Wright, S. 1938. Size of population and breeding structure in relation to evolution. Science 87:430-431.

Zabel, R. W., and P. S. Levin. 2002. Simple assumptions on age composition lead to erroneous conclusions on the nature of density dependence in age-structured populations. Oecologia 133:349-355.

Zwick, P. 1996. Variable egg development of Dinocras spp. (Plecoptera, Perlidae) and the stonefly seed bank theory. Freshwater Biology 35:81-100.

\section{APPENDIX}

A table showing ratios of multigenerational estimates of effective population size for individual populations of chinook salmon (Ecological Archives E091-065-A1). 